\title{
PENERAPAN ZERO ACCIDENT MELALUI PENYULUHAN KESELAMATAN DAN KESEHATAN KERJA (K3) KEPADA MITRA SMK
}

\author{
Widiyarini, Dian Jingga Permana, Zeny Fatimah Hunusalela
}

Teknik Industri, Fakultas Teknik dan Ilmu Komputer, Universitas Indraprasta PGRI

\begin{abstract}
Abstrak
Keselamatan dan kesehatan kerja (K3) di Indonesia telah lama mendapatkan perhatian khusus dari pemerintah. Secara umum jumlah kecelakaan kerja terus menurun tiap tahunnya sesuai data BPJS Ketenagakerjaan yaitu pada tahun 2015 terjadi 110.285 kasus kecelakaan kerja, tahun 2016 mengalami penurunan 4,6 persen atau ada 105.182 kasus kecelakaan kerja, dan pada bulan bulan Agustus tahun 2017 terdapat 80.392 kasus kecelakaan kerja. Didasari ini, tim abdimas Universitas Indraprasta PGRI melaksanakan kegiatan pengabdian masyarakat dengan memberikan pelatihan K3 kepada mitra SMK, bertujuan membekali pengetahuan K3 sejak dini kepada siswa SMK. Kegiatan pengabdian masyarakat menggunakan konsep pelatihan, peserta selain diberi penjelasan teoritis juga disertai contoh penerapan standar K3 di lingkungan kerja yang diperlihatkan secara visual serta praktek penanganan terhadap bahaya yang mengancam K3. Hasil dari kegiatan tersebut adalah antara lain peserta lebih waspada terhadap ancaman bahaya di tempat kerja, mampu melindungi dan memelihara K3 sehingga kinerja dapat meningkat, memastikan sumber produksi terpelihara dengan baik. Secara umum kegiatan pelatihan memberikan pengetahuan dan pengalaman kepada para siswa SMK dalam penerapan K3, diharapkan akan membangkitkan semangat mereka untuk menerapkan di tempat kerja nantinya sehingga tercapai zero accident.
\end{abstract}

Kata kunci: Pelatihan, Keselamatan dan Kesehatan Kerja, Zero Accident.

\begin{abstract}
Occupational health and safety (K3) in Indonesia has long received attention and support from the government, and since 1993 has been increased to achieve zero accident in each production process. In general, the number of work accidents continues to decline each year according to the BPJS Employment data, namely in 2015 there were 110,285 cases of workplace accidents, 2016 decreased by 4.6 percent or 105,182 cases of workplace accidents, and in August 2017 there were 80,392 work accident cases. Based on this, the team from Universitas Indraprasta PGRI carried out community service activities by providing K3 training to vocational partners, aiming to provide K3 knowledge early on to SMK students. Community service activities use the concept of training, in addition to being given theoretical explanations, participants are also accompanied by examples of the application of $\mathrm{K} 3$ standards in the work environment that are visually demonstrated and the practice of handling hazards that threaten K3. The results of these activities include participants being more vigilant about the threat of hazards in the workplace, being able to protect and maintain K3 so that performance can be improved, ensuring that production sources are well maintained. In general, the training activities provide knowledge and experience to Vocational students in implementing K3, which is expected to inspire them to apply in the workplace later so that zero accidents are achieved. Keywords: Training, Occupational Safety and Health, Zero Accident
\end{abstract}

Correspondence author: Widiyarini, widiya2513@ymail.com, Jakarta, Indonesia 


\section{PENDAHULUAN}

Pembangunan nasional Indonesia adalah upaya pemerataan pembangunan di segala bidang kehidupan yang dilaksanakan secara menyeluruh dan berkesinambungan, termasuk bidang Keselamatan dan Kesehatan Kerja (K3) (Umamamh, Denny, \& Kurniawan, 2015). Pembangunan kesehatan bertujuan memberikan kesadaran kepada setiap orang untuk berupaya hidup sehat supaya tercipta masyarakat yang sehat. Sebagaimana diuraikan dalam UU No.36 Tahun 2009 tentang Kesehatan pasal 162 yang berbunyi: Upaya kesehatan lingkungan ditujukan untuk mewujudkan kualitas lingkungan yang sehat, baik fisik, kimia, biologi, maupun sosial yang memungkinkan setiap orang mencapai derajat kesehatan yang setinggi-tingginya. Selanjutnya dalam pasal 162 ayat (2) yang dimaksud dengan lingkungan sehat mencakup lingkungan permukiman, tempat kerja, tempat rekreasi, serta tempat dan fasilitas umum.

Masalah keselamatan kerja di Indonesia telah lama mendapat perhatian dan dukungan dari pemerintah sejak ditetapkannya Undang-Undang Keselamatan Kerja Nomor 1 Tahun 1970. Bahkan sejak tahun 1993, keselamatan kerja telah ditingkatkan untuk mencapai kecelakaan nihil (zero accident) pada setiap proses produksi (Aria, 2015). Pemerintah Indonesia sejak empat tahun lalu telah menetapkan bulan Januari sebagai bulan Keselamatan dan Kesehatan Kerja (K3) dan diperingati setiap tanggal 12 Januari. Dalam peringatan Hari K3 tahun 2018 di Povinsi Kepulauan Riau, Menteri Tenaga Kerja, Hanif Dhakiri, mengatakan agar semua pihak untuk menerapkan standar K3. Baik di perusahaan maupun instansi pemerintahan. Peringatan Hari K3 tahun 2018 ini merupakan perjalanan program "Kemandirian Masyarakat Indonesia Berbudaya K3 Tahun 2020". Dengan mengusung tema "Melalui Budaya Keselamatan dan Kesehatan Kerja (K3) Kita Bentuk Bangsa yang Berkarakter."Hanif Dhakiri juga menyampaikan, memasuki tahun ke empat bulan K3 yang diperingati tahun ini jumlah kecelakaan kerja di dunia kerja mengalami penurunan. Berdasarkan data dari BPJS Ketenagakerjaan yang dia terima, jumlah kecelakaan kerja terus menurun tiap tahunnya."Tahun 2015 terjadi 110.285 kasus kecelakaan kerja. Kemudian pada tahun 2016, mengalami penurunan 4,6 persen atau ada 105.182 kasus kecelakaan kerja (Thamrin, 2015). Pada bulan bulan Agustus tahun 2017, BPJS Ketenagakerjaan hanya mendapat laporan 80.392 kasus kecelakaan kerja,".

Faktor kuat yang sering menyebabkan terjadinya kecelakaan kerja dan penyakit terhadap buruh/pekerja yang selama ini bekerja di perusahaan adalah karena lemahnya penerapan standar K3 di perusahaan. Akibat lemahnya penerapan K3 di perusahaan juga sangat berdampak kepada lingkungan sosial masyarakat sekitar. Dikalangan pekerja, banyak pekerja yang mengalami kecelakaan kerja akibat faktor perilaku tindakan tidak aman (unsafe action) dalam bekerja, penyebabnya adalah kurangnya pengetahuan pekerja tentang K3. Untuk itulah, satu-satunya cara mengurangi kecelakaan kerja dan gangguan kesehatan yang berdampak tidak baik pada buruh/pekerja dalam perusahaan adalah standar K3 harus dilaksanakan (Pradana \& Djastuti, 2015).

Salah satu aspek perlindungan tenaga kerja adalah perlindungan keselamatan. Perlindungan tersebut bertujuan agar para pekerja dapat bekerja secara aman sehingga dapat meningkatkan produktivitas kerja (Rahadian, Nursanti, \& Gustopo, 2015). Menurut Gary Dessler (2013), terdapat tiga penyebab kecelakaan yang utama:

1. Kemungkinan terjadinya kecelakaan Seperti berjalan di samping jendela kaca tepat pada saat seseorang melempar bola pada jendela tersebut, memiliki andil yang besar bagi timbulnya kecelakan. 
2. Kondisi yang tidak aman, meliputi: 1). Peralatan yang tidak safety. 2). Peralatan yang rusak. 3). Metode yang salah di sekitar mesin-mesin atau peralatan. 4) Gudang yang tidak aman: terlalu sesak atau banyaknya jumlah barang yang tersimpan didalam gudang sehingga terjadi kemacetan pada arus barang. 5).Penerangan yang tidak baik (menyilaukan, gelap). 6). Pengaturan udara tidak baik atau sumber udara kotor.

3. Perilaku yang tidak baik dari tenaga kerja, meliputi: 1). Tidak mengamankan peralatan. 2). Tidak menggunakan perlengkapan perlindungan. 3.) Membuang benda sembarangan. 4).Bekerja dengan kecepatan yang tidak aman (apakah terlalu cepat atau terlalu lambat menyebabkan tidak berfungsinya alat pengaman dengan memindahkan). 5). Menggunakan peralatan yang tidak aman atau dengan ceroboh. 6) Menggunakan prosedur yang tidak aman dalam memuat, menempatkan, mencampur dan mengkombinasi. 7).Mengambil posisi yang tidak aman di bawah beban yang tergantung. 8). Mengangkat barang dengan ceroboh, mengganggu/menggoda, bertengkar, bermain-main dan sebagainya.

Mangkunegara (2011:161), menyatakan keselamatan kerja menunjukkan pada kondisi yang aman di tempat kerja. Indikator Keselamatan Menurut Suma'ur (1996) adapun indikator - indikator keselamatan kerja meliputi :

1. Tempat kerja merupakan lokasi dimana para karyawan melakukan pekerjaan.

2. Mesin dan Peralatan Mesin dan Peralatan adalah bagian dari kegiatan operasional dalam proses produksi yang biasanya berupa alat - alat berat dan ringan.

Keselamatan dan kesehatan kerja (K3) merupakan faktor yang paling penting dalam pencapaian sasaran tujuan peroyek. Hasil yang maksimal dalam kinerja biaya, mutu dan waktu tiada artinya bila tingkat keselamatan kerja terabaikan. Indikatornya bisa berupa tingkat kecelakaan kerja yang tinggi, seperti banyak tenaga kerja yang meninggal, cacat permanen serta instalasi proyek yang rusak, selain kerugian materi yang besar (Husen, 2009).

Bahaya atau hazard adalah suatu sumber yang dapat menimbulkan kerugian baik berupa luka-luka terhadap manusia, penyakit, kerusakan properti, lingkungan atau kombinasinya (Frank bird-loss control management). Sedangkan menurut OHSAS (Occupational Health and Safety Assesment Series) 18001 hazard adalah sumber, situasi atau tindakan yang berpotensi menimbulkan kerugian dalam hal luka-luka atau penyakit terhadap manusia. 2.3 Risiko Risiko adalah seberapa besar peluang potensi hazard menjadi kenyataan (Kurniawidjadja, 2010).

\section{METODE PELAKSANAAN}

Pelaksanaan kegiatan Pengabdian terhadap masyarakat yang berjudul "Penerapan Zero Accident melalui Penyuluhan Keselamatan Dan Kesehatan Kerja (K3)Kepada Mitra SMK" yang bekerja sama dengan 2 mitra, adapun mitra terdiri dariSMK Farmasi Avicenna Cileungsi Bogor dan SMK Al-Hidayah 1 Jakarta Selatan. Kegiatan ini dapat terlaksanaan berdasarkan hasil koordinasi dengan pihak sekolah, yang menginginkan membekali pengetahuan dasar - dasar K3 kepada para siswa dengan harapan agar sejak dini telah tertanam perilaku kerja sesuai prosedur keamanan sehingga dapat melindungi 
diri sendiri maupun orang-orang yang ada di sekitar lingkungan kerja, serta mampu menjaga alat produksi berfungsi secara aman.

\section{Tahapan kegiatan}

Kegiatan ini menggunakan konsep pelatihan, dimana peserta tidak hanya menerima penjelasan teoritis tetapi juga disertai contoh penerapan standar K3 di lingkungan kerja yang diperlihatkan secara visual serta praktek penanganan terhadap bahaya yang mengancam K3. Sehingga peserta pelatihan memiliki gambaran kondisi ril serta mampu mempraktekkannya. Untuk melaksanakan kegiatan tersebut digunakan beberapa metode dalam kegiatan penyuluhan ini, adapun metode terdiri dari:

1. Ceramah.

Selain memberikan materi K3 juga untuk memotivasi peserta pelatihan tentang pentingnya penerapan $\mathrm{K} 3$ di tempat kerja.

2. Diskusi (Tanya Jawab).

Metode tanya jawab sangat penting bagi para peserta pelatihan, baik pada saat menerima penjelasan tentang prosedur K3, maupun saat mempraktekkan penanganan terhadap bahaya yang mengancam K3. Metode ini memungkinkan para siswa menggali pengetahuan sebanyak-banyaknya tentang penerapan $\mathrm{K} 3$, termasuk kendala yang dihadapi oleh pekerja maupun perusahaan.

3. Evaluasi

Evaluasi sangat penting diberikan kepada para peserta di akhir kegiatan, evaluasi dilaksanaakan melalui tahapan tes tertulis kepada para peserta kegiatan.Tahapan evaluasi dilakukan untuk mengetahui sampai sejauh manapara peserta dapat memahami pentingnya penerapan dan pelaksanaan K3 di lingkungan kerja.

\section{HASIL DAN PEMBAHASAN}

Berdasarkan permasalahan dan metode yang digunakan dalam pelaksanaan kegiatan Program Penerapan Ipteks bagi Masyarakat (PPIM) untuk tema "Penerapan Zero Accident melalui Penyuluhan Keselamatan Dan Kesehatan Kerja (K3) Kepada Mitra SMK"yang diselenggarakan oleh Universitas Indraprasta PGRI Program Studi Teknik industri dan bekerja sama dengan SMK Farmasi Avicenna Cileungsi Bogor dan SMK Al-Hidayah 1 Jakarta Selatansebagai mitra, maka diperoleh hasil bahwa siswa siswasaat initelah memahami tentang :

1. Pengetahuan para siswa SMK terhadap pentingnya K3 dalam bekerja, bahwa manusia bukan sekedar alat produksi tapi merupakan aset perusahaan yang sangat berharga sehingga harus dilindungi keselamatannya.

2. Keselamatan pada dasarnya adalah kebutuhan setiap manusia dan menjadi naluri setiap makluk hidup, melalui pemahamannya tentang dasar - dasar K3 diharapkan dapat dijadikan sebagaibudaya K3 di lingkungan sekolah.

3. Saat ini, para siswa telah mengetahui pentingnya penerapan K3 di lingkungan kerja dapat mencegah dan mengurangiangka kecelakaan kerja dan gangguan kesehatan.

Sebelum pelaksanaan kegiatanPenyuluhan Program Penerapan Ipteks bagi Masyarakat (PPIM) dilaksanakan, siswa - siswi belum memiliki pemahaman dasar tentang dasar - dasar pelaksanaan K3 di lingkungan kerja.Sebagai perserta didik yang mengikuti jenjang pendidikan menenggah kejuaruan ini, mereka dipersiapkan agar bisa 
langsung terjun dalam dunia kerja setelah lulus nanti. Pengetahuan dasar - dasar mengenai K3 sangalah diperlukan bagi para siswa ketika berada dalam dunia kerja, hal ini sesuai dengan tujuan dari K3 itu sendiri. Adapun tujuan pelaksanaan K3 adalah :

1. Melindungi para pekerja dan orang lain di tempat kerja

2. Menjamin agar setiap sumber produksi dapat dipakai secara aman dan efisien

3. Menjamin proses produksi berjalan lancar

Kegiatan pelatihan sangat membantu dalam memberikan pengetahuan kepada para siswa SMK tentang K3, meliputi Keamanan, Kesehatan, dan Keselamatan Kerja. Sekaligus membekali para lulusan SMK dalam menerapkan prosedur K3 di tempat kerja. Karena presentasi lulusan SMK yang memilih bekerja sangat tinggi dibandingkan dengan yang melanjutkan ke Perguruan Tinggi. Lulusan SMK memiliki tiga peluang, yakni berwirausaha, bekerja, dan melanjutkan ke Perguruan Tinggi. Direktur SMK, Kementerian Pendidikan dan Kebudayaan (Kemdikbud) Mustaghfirin Amin mengatakan, baru $10 \%$ lulusan SMK terserap Perguruan Tinggi, sementara $90 \%$ terserap dunia industri. Sehingga penerapan K3 sangat perlu untuk dipahami sejak dini oleh para siswa SMK sebelum masuk ke dunia industri. Hal ini penting sebagaimana tertuang dalam Undang-Undang Ketenagakerjaan No. 13 Tahun 2003 pasal 87.

Adapun bentuk kegiatan pelaksanaan kegiatan Penyuluhan Program Penerapan Ipteks bagi Masyarakat (PPIM) yang dilaksanakan diSMK Farmasi Avicenna Cileungsi Bogor dan SMK Al-Hidayah 1 Jakarta Selatan dapat terlihat pada gambar - gambar di bawah ini :

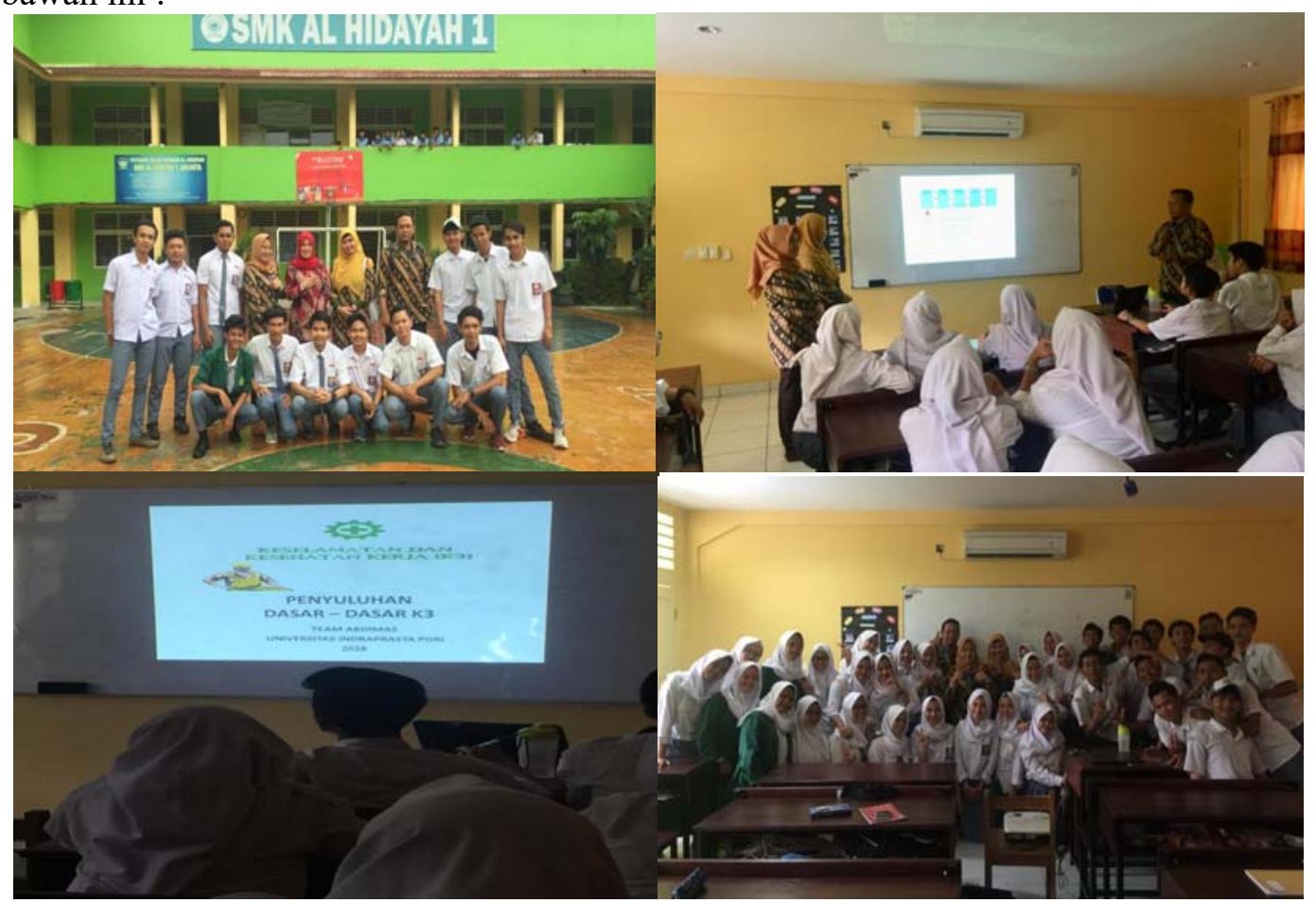

Gambar 1 Kegiatan Pengabdian kepada Masyarakat di SMK 


\section{SIMPULAN}

Dalam Pelaksanaan kegiatan Program Penerapan Ipteks bagi Masyarakat (PPIM) yang berjudul "Penerapan Zero Accident melalui Penyuluhan Keselamatan Dan Kesehatan Kerja (K3)Kepada Mitra SMK" yang bekerja sama dengan 2 mitra, adapun mitra terdiri dariSMK Farmasi Avicenna Cileungsi Bogor dan SMK Al-Hidayah 1 Jakarta Selatan pada tanggal 6November 2018 dan 7 November 2018, maka dapat disimpulkan bahwa :

1. Mitra telah memiliki pengetahuan dan memahami Pengetahuan tentang pentingnya K3 dalam bekerja.

2. Keselamatan pada dasarnya adalah kebutuhan setiap manusia dan menjadi naluri setiap makluk hidup.

3. Pentingnya penerapan K3 di lingkungan kerja dapat mencegah dan mengurangi angka kecelakaan kerja dan gangguan kesehatan.

\section{DAFTAR PUSTAKA}

Agung S. (2016). Himpunan Peraturan Perundang-Undangan Keselamatan dan Kesehatan Kerja. Jakarta: Mediatama.

Anizar. (2009). Teknik Keselamatan dan Kesehatan Kerja di Industri. Yogyakarta: Graha Ilmu.

Aria. (2015). Pengaruh Keselamatan dan Kesehatan Kerja terhadap Kepuasan Kerja Karyawan (Studi Pada Karyawan bagian Produksi PT Hankook Tire Indonesia, Cikarang). Jurnal Administrasi Bisnis (JAB), 29 (1), 103-111

John R. (2009). Kesehatan dan Keselamatan Kerja: Ikhtisar. Jakarta: Erlangga.

Kemendikbud. (2013). Panduan Pelaksanaan Penelitian dan Pengabdian kepada Masyarakat di Perguruan Tinggi. Jakarta: Dirjendikti

Kesuma, et al. (2015). Pengaruh Kompensasi, Pendidikan dan Pelatihan Program Keselamatan Kerja terhadap Kinerja Karyawan di Hotel Kuta Paradiso Kuta, Bandung. Jurnal Vol.4. No.2.

KSBSI. 2018. Berita online Konfederasi Serikat Buruh Sejahtera Indonesia http://www.ksbsi.org/index.php/baca/lengkap/504.

Mankunegara P. A. (2011). Manajemen Sumber Daya Manusia Perusahaan. PT. Reaja Rosda Karya, Bandung

Pradana, A. A., \& Djastuti. (2015). Implementasi Program Keselamatan dan Kesehatan Kerja serta Tantangan yang akan dihadapi PT PLN (Persero) PLTU TJB Jepara Dalam Upaya Mempertahankan Zero Accident. 4, 1-15. https://doi.org/10.1146/annurev.polisci.7.012003.104840

Rahadian, D., Nursanti, E., \& Gustopo, D. (2015). Perencanaan Kontrol Kecelakaan kerja Munuju Zero Accident Pada Industri Pabrik Gula NHB. 1(2), 17-21. 
Sugiyono, (2013). Metode Penelitian Bisnis. Bandung: CV. Alfabeta.

Tarwaka. (2014). Keselamatan dan Kesehatan Kerja : Manajemen dan Implementasi K3 di Tempat Kerja. Surakarta: Harapan Press.

Thamrin, H. M. (2015). Pencegahan Kecelakaan Kapal Ke Titik Nol (Zero Accident). Jurnal Ilmiah Widya, 3, 110-116.

Umamamh, A., Denny, H. M., \& Kurniawan, B. (2015). Analisis Upaya Pencegahan dan Pengendalian Kecelakaan Kerja pada Sebuah Pabrik Semen di Tuban A'izzatul Umamah, Hanifa Maher Denny, Bina Kurniawan. Jurnal Kesehatan Masyarakat, 3(April)

Undang-Undang Republik Indonesia Nomor 36 Tahun 2009 tentang Kesehatan

Undang-Undang Republik Indonesia Nomor 1 Tahun 1970 tentang Keselamatan Kerja

Undang-Undang Republik Indonesia Nomor 13 Tahun 2003 tentang Ketenagakerjaan

Yuli, S. B. C. (2005). Manajemen Sunber Daya Manusia, Cetakan Pertama, UMM Press, Malang 